\title{
Cultural disruption and challenges for anthropology in the development of multicultural communities
}

\section{Disrupsi budaya dan tantangan antropologi dalam pembangunan masyarakat multikultural}

\author{
A.A. Ngurah Anom Kumbara1, A.A Sagung Kartika Dewi², Mayske Rinny Liando³, \\ Made Wiasti ${ }^{4}$ \\ ${ }^{1}$ Faculty of Cultural Studies, Udayana University, Indonesia. Email: anom_kumbara@unud.ac.id \\ ${ }^{2}$ Faculty of Economic and Business, Udayana University, Indonesia. Email: sagung_kartika@unud.ac.id \\ ${ }^{3}$ Faculty of Language and Art, Manado State University, Indonesia. Email: rinny_lindo@unima.ac.id \\ ${ }^{4}$ Faculty of Cultural Studies, Udayana University, Indonesia.Email: made_wiasti@unud.ac.id
}

\begin{tabular}{|c|c|}
\hline ARTICLE INFO & ABSTRACT \\
\hline $\begin{array}{l}\text { Keywords: } \\
\text { Cultural Disruptions; } \\
\text { Globalization; Culture } \\
\text { Capital; multiculturalism; } \\
\text { Anthropology. } \\
\text { How to cite: } \\
\text { Kumbara, AA.N.A., Dewi, } \\
\text { AA.S.K., Liando, M.R., } \\
\text { Wiasti, M. (2020). Disrupsi } \\
\text { budaya dan tantangan } \\
\text { antropologi dalam } \\
\text { pembangunan masyarakat } \\
\text { multikultural. ETNOSIA: } \\
\text { Jurnal Etnografi Indonesia. } \\
\text { 5(1):5 -14. }\end{array}$ & $\begin{array}{l}\text { This article intends to discuss the phenomenon of cultural } \\
\text { disruptions due to globalization and the industrial revolution } 4.0 \\
\text { which have paradoxical consequences for empirical life and in the } \\
\text { academic world, especially in the field of anthropology. This study } \\
\text { uses a library method with interpretive analysis techniques. The } \\
\text { results concluded that globalization and the industrial revolution } 4.0 \\
\text { had fundamentally changed the order of the people's cultural values. } \\
\text { This is a challenge for anthropology to reflect on epistemology and } \\
\text { axiology as a logical consequence of changes in the ontology. In the } \\
\text { context of Indonesia, the presence of anthropology is expected to be } \\
\text { able to explore the plurality of national culture that can be narrated } \\
\text { on the academic stage. At the same time, it can be also a productive } \\
\text { cultural capital to overcome the challenges of diversity, becoming a } \\
\text { driver of change, and strengthening national identity. }\end{array}$ \\
\hline $\begin{array}{l}\text { DOI: } \\
\text { 10.31947/etnosia.v5i1.8679 }\end{array}$ & \\
\hline
\end{tabular}

\section{Pendahuluan}

Globalisasi tampaknya menjadi wacana yang paling menarik dibicarakan dalam studistudi kebudayaan dewasa ini. Mengingat pengaruhnya yang begitu kuat yang secara dramatis telah mengubah tatanan dan nilai-nilai sosial masyarakat di pelbagai belahan dunia (Fukuyama, 1999; Ritzer \& Goodman, 2005). Setiap masyarakat yang telah tersentuh globalisasi pasti akan mengalami perubahan karena bukan globalisasi yang menyesuaikan dengan pola tradisi masyarakat, melainkan budaya global yang mengintegrasikan masyarakat ke dalam suatu tatanan global (Abdullah, 1995). 
Friedman (2002) menyebut tiga konsep yang nyaris selalu ditemukan dalam setiap definisi globalisasi, yaitu interdependensi, integrasi, dan kesalingterkaitan. Beberapa istilah turunan globalisasi, seperti global village (McLuhan, 1994), penyempitan dunia (Robertson, 1995), dunia yang dilipat (Pilliang, 1998), atau borderless world (Ochame, 1999), seluruhnya mengacu pada kesalinghubungan dan interkoneksi yang mengglobal.

Sejumlah kalangan meyakini bahwa globalisasi berpretensi menciptakan keseragaman budaya (cultural homogenities) karena masyarakat dari etnis, ras, bangsa, dan agama yang berbeda-beda cenderung mengkonsumsi barang, simbol, nilai, gaya hidup, informasi, serta ideologi yang sama. Abdullah (2006a, 2006b) menegaskan bahwa gejala munculnya pasar dan masyarakat konsumen sebagai kekuatan baru dalam membangun duniakehidupan sehari-hari. Akan tetapi, Naisbitt (1994) melihat bahwa keseragaman dan hilangnya perbedaan identitas kultural hanyalah mitos globalisasi yang terlampau dibesar-besarkan. Semakin dunia terkoneksi secara global, justru tindakan sebagian masyarakat semakin primordial. Semakin budaya terakulturasi menuju pembentukan kultur universal, keinginan untuk menunjukkan identitas yang berbeda dengan bangsa lain juga semakin menguat. Pendek kata, globalisasi senantiasa akan menyajikan gejala paradoks, tidak disangka-sangka, dan menampilkan diri sebagai sesuatu yang sungguhsungguh nyata.

Dalam tatanan masyarakat yang multipolar dan multisivilisasional seiring berlangsungnya proses global dengan segala paradoksnya, posisi kebudayaan dipandang semakin strategis dalam menentukan eksistensi serta masa depan suatu negara-bangsa. Dari pemikiran Fukuyama (1992) dan Huntington (1996) dapat dirajut benang merah mengenai gambaran masa depan dunia bahwa kebudayaan dan peradaban diprediksi akan memiliki andil lebih besar dalam menentukan integrasi dan kemajuan, atau malah sebaliknya, menjadi faktor konflik dan kemunduran suatu masyarakat, melampaui sekedar urusan politik, ekonomi, maupun sosial. Wacanawacana kebudayaan dan agama dipandang akan semakin produktif untuk dikapitalisasi dalam berbagai kepentingan karena hanya melalui wacana inilah, perbedaan niscaya ditemukan dan dikalkulasikan sebagai keunggulan potensial, saat bidang-bidang kehidupan yang lain nyaris seluruhnya seragam. Implikasinya bahwa politik identitas, isu-isu lokalitas, dan sentimen primordial lainnya diprediksi akan meningkat gejalanya di tengah-tengah dunia kehidupan yang semakin mengglobal.

Fenomena tersebut memberikan tantangan besar dalam pembangunan masyarakat multikultural di Indonesia. Pada satu sisi, keanekaragaman budaya dapat mengancam keutuhan bangsa, tetapi pada sisi yang lain juga merupakan potensi besar untuk membangun kemajuan. Disrupsi budaya mengisyaratkan pentingnya menciptakan alternatif-alternatif kultural yang mampu mendialogkan kepentingan lokal, nasional, dan global dalam menyikapi kemajemukan budaya bangsa. Kebudayaan harus bergerak secara dialektis antara pelestarian dan perubahan, tradisi dan inovasi. Bagaimana mengelola ketegangan-ketegangan budaya merupakan kunci untuk memahami stabilitas masyarakat modern (Lull, 1998). Makalah ini hendak membahas masalah dirupsi budaya dan tantangan epistimologi dan aksiologi antropologi dalam dunia kehidupan empirik dan teoritis. Secara praxis kehadiran antropologi dalam konteks ke-Indonesiaan diharapkan agar pluralitas budaya bangsa dapat dieksplorasi, dinarasikan dalam 
panggung akademis dunia, sekaligus dapat dijadikan modal budaya (culture capital) yang produktif untuk mengatasi tantangan-tantangan kebhinekaan, menjadi penggerak perubahan, dan memperkuat jati diri bangsa.

\section{Diskusi}

\section{- Disrupsi budaya dan tantangan antropologi}

Globalisasi menciptakan perubahan mendasar dalam tatanan dan nilai-nilai sosial yang sungguh-sungguh berbeda dari zaman sebelumnya. Kendati demikian, globalisasi merupakan kondisi ketidakmenentuan yang arahnya sulit diprediksi. Giddens (2000) memaknai globalisasi sebagai runaway world, dunia yang berubah-ubah, penuh risiko, dapat melumpuhkan kultur lokal, tetapi juga membangkitkannya kembali. Disrupsi budaya menjadi keniscayaan, manakala globalisasi berpotensi mengacaukan budaya mapan, tetapi juga menyediakan rentang alternatif untuk melakukan serangan balik. Kellner (2002) memberikan contoh bahwa internet merupakan media mempromosikan globalisasi kapitalis, tetapi saat bersamaan internet juga dijadikan saluran sekelompok orang untuk menentang kapitalisme. Oleh karenanya, teori-teori globalisasi kultural dalam berbagai kasus senantiasa terbelah pada perbedaan cara pandang mengenai pengaruh globalisasi terhadap meningkatnya homogenitas atau heterogenitas budaya dalam interaksi lokal dan global (Ritzer \& Goodman, 2005).

Interaksi yang cenderung meningkatkan homogenitas kultural ditemukan dalam kasus imperialisme budaya, yaitu hegemoni negara dunia pertama (core nation) yang memengaruhi kebudayaan di seluruh dunia karena kesenjangan informasi. Herbert Schiller et.all, mendeskripsikan imperialisme budaya sebagai kontrol dan kepemilikan industri komunikasi internasional oleh negara dunia pertama yang memengaruhi budaya negara dunia ketiga (McPhail, 2014:40). Perkembangan kebudayaan dan komunikasi dunia, tidak dapat disangkal lagi memang menunjukkan kekuatankekuatan homogenisasi seperti format media, teknik iklan, internasionalisasi bahasa Inggris, mode pakaian, makanan cepat saji, dan sebagainya yang memengaruhi kesadaran masyarakat dunia. Ruang pengaruh ini memperkenalkan dan memperkuat nilai-nilai serta praktik-praktik tertentu yang menjadi standar budaya masyarakat.

Namun demikian, pengaruh politik, ekonomi, pendidikan, dan kebudayaan tidak sepenuhnya mampu membuat konteks budaya selurunya menjadi seragam karena selalu berinteraksi dengan kondisi lokal yang beranekaragam. Walaupun dipraktikkan dalam skala global, kekuatan-kekuatan budaya yang menghomogenisasi akan selalu berhadapan dengan ideologi dan tradisi yang beraneka ragam, justru menghasilkan berbagai dialog yang heterogen (Appadurai, 1990, Lewellen,2002). Heterogenitas kultural terjadi tatkala kultur lokal dan global saling berinteraksi serta menciptakan perpaduan yang mengarah pada pencangkokan budaya atau hibritasi (Ritzer \& Goodman, 2005). Kekuatan modernitas jelas mengubah wajah kebudayaan, termasuk hubungan-hubungan politik dan ekonomi dunia, tetapi globalisasi yang meresap sebagai akibatnya lebih sebagai organisasi kebhinekaan daripada replika keseragaman (Hannerz, 1990). Robertson (1995) mengajukan glokalisasi yang menekankan bagaimana proses-proses global dipengaruhi atau bahkan ditumbangkan oleh penerapan, 
penafsiran, dan adaptasi budaya lokal sehingga melahirkan suatu yang nyata berbeda, yakni global-lokal (glocal).

Disrupsi budaya dalam dialektis homogenitas dan heterogenitas budaya menjadi tantangan bagi antropologi untuk mendefinisikan kembali kebudayaan sebagai status ontologinya. Mengaburnya batas-batas wilayah, politik, sosial, dan ekonomi, mensyaratkan definisi kebudayaan yang lebih kritis dan terbuka bahwa kebudayaan tidak hanya dapat dipahami sebagai sesuatu yang generik ' given', tetapi diferensial yang terikat ruang, waktu, dan interelasinya dengan berbagai konteks (Abdullah, 2006b). Kebudayaan adalah pengalaman dalam hidup sehari-hari, berbagai teks, praktik, nilai, dan makna semua orang dalam menjalani hidup mereka (Barker, 2005). Storey (2007) mengartikan 'budaya' bukan konsep yang didefinisikan dalam kajian lain, seperti objek keadiluhungan estetis (seni tinggi), proses perkembangan estetik, intelektual, maupun spritual, melainkan budaya sebagai teks dan praktik hidup sehari-hari.

Perubahan status ontologi tersebut menjadi tantangan berikutnya dalam hal epistemologi antropologi, baik pendekatan, paradigma, perspektif, maupun metodenya. Antropologi kekinian tentunya tidak harus meninggalkan seluruh pengetahuan dan cara kerja etnografi klasik (dengan pendekatan fungsionalisme struktural dan evolusi) yang kental terkait dengan globalisasi karena setiap perubahan tidak mungkin mengubah sepenuhnya tatanan nilai budaya masyarakat. Perubahan kebudayaan, walaupun memungkinkan terjadi secara revolusioner, tetapi kecenderungan umum tetaplah akan mengikuti garis edar tertentu sehingga meniscayakan untuk menemukan jejak-jejak transformasinya (Sutrisno, 2008). Namun demikian, sifat kebudayaan yang tidak kaku dan beku juga harus disikapi dengan membuka segala kemungkinan untuk menemukan pendekatan atau paradigma yang terbarukan, tanpa harus mengganti standar pengetahun etnografi yang sudah ada, untuk menjawab kritik terhadap persoalan representasi, autentitas, obyektivitas, dan netralitas etnografer (Marcuss, 1990, Putnam,1981). Berkenaan dengan itu, pengembangan perspektif antropologi imajinasi (anthropological imagination) (Hastrup, 1995), etnografi kritis (cretical ethnography) (Madison, 1990) dalam memahami interelasi antar wacana, antar teks dan konteks yang luas, yang berkelindan dan tidak lepas dari persoalan politik ekonomi dan kekuasaan menjadi langkah yang krusial. Untuk memahami kebudayaan yang telah bergeser dari bounded system ke boundaries society, setidak-tidaknya ada empat syarat dan domain yang patut diperhatikan dalam studi kebudayaan masa kini yakni (1) pendefinisian ulang atau setting studi dilakukan- dari culture area menjadi subculture area yang tidak terikat lagi oleh batas-batas geografis (deteritorialisasi budaya); (2) pentingnya pengakuan keberadaan mengenai suatu representasi dengan rasionalismenya sendiri; (3) pengaruh teknologi dan media yang mengubah definisi komunitas atas sesuatu hal, dan (4) memperhatian hubungan-hubungan kebudayaan dengan demensi politik ekonomi dan kekuasaan.

Berikutnya, disrupsi budaya juga menyajikan tantangan bagi antropologi dalam tanggung jawab aksiologinya terhadap masyarakat. Disrupsi bukanlah kekacauan yang melulu berimplikasi negatif, melainkan perluasan rentang alternatif yang meniscayakan berbagai inovasi berkembang (innovative disruption) melampaui kemapanan yang telah terbangun, bahkan acapkali memberi kejutan yang tidak terprediksikan sebelumnya. 
Globalisasi sebaiknya dipahami sebagai himpunan yang kompleks dari arus manusia, materi, dan simbol yang berinteraksi, bahkan bertentangan, yang melahirkan sikap dan praktik budaya beragam serta terus menerus memodifikasi secara bervariasi faktorfaktor kekuasaan, sosial, politik, dan budaya yang telah mapan. Apabila perubahan yang dirintis dapat memberi keuntungan tanpa merusak hubungan budaya, maka hasilnya akan baik sekali (Depari \& MacAndreus, 1998). Artinya, antropologi dituntut mampu memikul tanggung jawab aksiologi (praxis ruler) untuk membongkar praktik kekuasaan, ideologi, politik ekonomi dan kultural yang menghambat transformasi masyarakat. Studi-studi kebudayaan harus diarahkan sebagai upaya emansipatoris, partisipartoris, pencerahan, dan penyadaran yang sarat nilai.

\section{- Menggali modal budaya (culture capital exploration)}

Kebhinekaan bangsa Indonesia harus dilihat dan dikelola dengan skema multikulturalisme sehingga perbedaan dapat ditransformasikan sebagai modal budaya (cultural capital) yang produktif bagi pembangunan. Mengingat basis multikulturalisme adalah menggali kekuatan suatu bangsa yang tersembunyi dalam kebudayaan yang berjenis-jenis (Tilaar, 2004:92). Modal budaya inilah yang mesti digali dan digalang sebagai kekuatan nasional. Bukan hanya untuk mengukuhkan kebudayaan nasional, melainkan agar seluruh elemen bangsa dengan segenap nilai budayanya dapat berkontribusi positif dan berpartisipasi aktif dalam pembangunan secara adil dan setara. Antropologi sebagai pioner studi kebudayaan tentu memiliki tanggung jawab dalam upaya tersebut, apalagi pada era disrupsi ini. Multikulturalisme menghendaki studi kebudayaan yang mampu menguraikan interaksi kultur lokal, nasional, dan global terutama dalam isu-isu seputar identitas dan representasi budaya.

Imperialisme budaya melalui globalisasi media meniscayakan individu mengkonsumsi nilai-nilai dari luar yang berbeda dengan pakem budayanya sendiri tanpa kontrol dari lingkungannya. Nilai tersebut diadopsi, diadaptasi, dan diinternalisasikan terus menerus dalam praktik kehidupan sehari-hari sehingga disadari maupun tidak, telah menjadi budayanya. Di lain pihak, ia juga terikat dengan sistem nilai yang diwarisi dari tradisi dan komunitasnya. Pergulatan berbagai nilai ini membentuk identitas diri yang terbelah sehingga komunitas tidak dapat lagi dijadikan acuan untuk menggambarkan sebuah sistem budaya. Pada gilirannya, budaya suatu komunitas hanyalah representasi kolektif dari diri yang berbeda-beda. Relasi ini juga terjadi pada komunitas negarabangsa (nation-state) sebagai "rumah baru" dari masyarakat yang beragam. Anderson (1999) memaknai bangsa sebagai komunitas terbayang (imagined community), komunitas politik yang mencakup jutaan orang, yang tidak pernah saling mengenal, bahkan mungkin tidak saling pernah melihat, berinteraksi, tetapi mereka tetap diharapkan membayar pajak, memberikan pengabdian, bahkan mengorbankan nyawanya demi bangsanya.

Kebhinekaan yang bersifat warisan 'given', kemudian harus dipandang sebagai realitas yang dibangun 'construct' dalam konteks negara-bangsa. Hal ini karena kebhinekaan yang diwarisi harus ditransformasikan dalam identitas nasional. Transformasi kebhinekaan dalam identitas nasional mengisyaratkan pentingnya mengurai relasi etnisitas dan sentimen primordial lainnya dengan nasionalisme. Kedua konsep ini sebenarnya berkerabat, tetapi dalam praktik, perbedaan keduanya sangat rumit 


\section{P-ISSN: 2527-9319; E-ISSN: 2548-9747}

(Eriksen, 1993, 2015). Kebhinekaan sebagai teks sosial maknanya tidak stabil, konstruktif, dan senantiasa dipengaruhi berbagai konteks. Oleh karena itu, multikulturalisme tetap menyimpan bahaya laten yang serius karena keanekaragaman nilai, visi tentang kehidupan yang baik, dan interpretasi sejarah dapat menajamkan sekat-sekat perbedaan masyarakat (Parekh, 2007, Tilaar, 2004). Setidaknya terdapat tiga tantangan dalam membangun multikulturalisme dewasa ini, yaitu (1) hegemoni Barat di bidang Iptek, politik, ekonomi, sosial, dan budaya melalui wacana modernisasi terutama diarahkan pada negara-negara berkembang; (2) esensialisasi budaya, yakni menggali esensi budaya sendiri yang menyuburkan xenopobhia dan etnosentrisme; dan (3) globalisasi yang berpretensi melunturkan jati diri dan identitas khas setiap bangsa seiring mencairnya batas-batas politik dan kebudayaan. Tiga tantangan tersebut harus menjadi perhatian antropologi dalam mengembangkan studi-studi kebudayaan yang lebih reflektif dan produktif ke depan.

Hegemoni Barat melalui modernisasi tentu sulit dilawan, walaupun tidak tertutup kemungkinan untuk melakukan counter hegemony. Kritik orientalisme yang dilontarkan Said (2001) menghentakkan kesadaran bahwa dikotomi Timur dan Barat harus dilihat sebagai hubungan kekuasaan, dominasi, dan berbagai derajat hegemoni yang kompleks. Hubungan ini pada derajat tertentu bersifat reversible yang pada gilirannya dapat berbalik arah. Studi-studi yang dilakukan Weber (1958), Bellah (1985), dan Huntington (1996) menegaskan bahwa ide-ide kemajuan dapat ditemukan pada semua kebudayaan. Hal ini memberikan peluang bagi antropologi untuk lebih mengapresiasi pengembangan indigenous anthropology atau etnosain untuk menemukan berbagai pengetahuan dan kearifan lokal yang tersimpan di dalam kekayaan budaya bangsa. Keberhasilan India dan China dalam pengembangan sistem pengobatan tradisionalnya dapat dijadikan salah satu inspirasi dalam pengembangan antropologi ke depan sehingga mampu berkontribusi positif dan nyata terhadap kesejahteraan masyarakat. Esensialisasi budaya yang direpresentasikan dengan pernyataan bahwa suatu etnis, budaya, dan agama memiliki nilai keunggulan esensial yang tidak ditemukan dalam budaya lain mengandung bahaya etnosentrisme yang harus disikapi secara serius. Gerakan etnonationalism dan religionationalism sebagai identitas politik baru 'yang lain' dari nasionalisme negara-bangsa belakangan ini memang cukup mengkhawatirkan. Paham ini membangun imajinasi bahwa negara dengan komunitas etnis atau agama yang seragam dianggap akan lebih baik daripada yang beragam (Suaedy, dkk., 2007). Studi-studi antropologi sejak lama telah mempersoalkan esensialisme budaya sebagaimana dilakukan para pengusung relativisme budaya yang dipopulerkan oleh Frans Boaz (1911) bahwa suatu kebudayaan tidak dapat dinilai berdasarkan cara pandang budaya lain, kecuali oleh masyarakatnya sendiri (Koentjaraningat, 1980; Goo, 2013). Pandangan ini kiranya relevan ditinjau kembali dalam studi-studi antropologi ke depan agar eksemplar-eksemplar etnografi yang muncul tidak mendiskreditkan dan menstigmasi suatu komunitas budaya. Pengakuan dan penghargaan atas kekhasan suatu entitas budaya sebagai 'kebenaran lain' harus dijadikan misi antroplogi dalam konteks multikulturalisme.

Ancaman homogenisasi budaya akibat globalisasi yang membuka pintu masuknya berbagai ideologi, gaya hidup, dan budaya asing terutama melalui saluran media telah menjadi perhatian para teoretisasi globalisasi. Akan tetapi, Sahlin (1994) juga 
menegaskan bahwa globalisasi hendaknya tidak dipandang hanya terjadi akhir-akhir ini, tetapi sesungguhnya telah terjadi ketika suatu bangsa telah berkomunikasi dengan bangsa lain. Kemajemukan budaya tidak muncul karena suatu bangsa terisolasi, tetapi justru karena kontak secara terus menerus dengan budaya yang berbeda. Studi-studi sejarah, arkeologi, dan antropologi mengenai local genious bangsa Indonesia menghadapi masuknya budaya asing sejak masa prasejarah, Hindu-Buddha, Islam, hingga kolonial menunjukkan bahwa bangsa Indonesia mempunyai karakter adaptif yang tinggi terhadap budaya asing (Ayatroehaedi, 1986). Karakter inilah dapat dibangun dan dikembangkan melalui studi-studi antropologi yang lebih inovatif dengan memanfaatkan teknologi informasi kekinian. Digitalisasi budaya bangsa lewat media televisi dan internet yang mulai marak belakangan ini patut diapresiasi, diadaptasi, dan tentu partisipasi antropologi dalam menyuguhkan potret kekayaan budaya bangsa dalam industri budaya massa harus ditingkatkan.

Ringkasnya, peran dan tanggung jawab antropologi dalam membangun masyarakat multikultural dapat dimulai dengan mengungkap berbagai modal budaya yang tersimpan dalam keragaman budaya bangsa. Selanjutnya, modal budaya ini mampu dioptimalkan untuk mengkonstruksi identitas nasional dengan implikasi psikis yang menyenangkan. Identitas nasional diperlukan bukan saja untuk membangun kebanggaan berbangsa, tetapi lebih penting dari itu adalah membangun rasa kasih sayang, solidaritas, dan tanggung jawab bersama terhadap kepentingan nasional. Pemahaman tentang identitas nasional harus mampu menyatukan seluruh anggotanya pada seputar pemahaman identitas, memberi fokus serta energi pada rasa memiliki bersama, membangun citra diri kolektif, mengelola kebaikan-kebaikan yang relevan, memfasilitasi reproduksi komunitas dan kesinambungan antargenerasi, menjaga kesetiaan umum, serta menata kehidupan moral dan politik. Dengan kata lain, identitas nasional harus diarahkan untuk membangun rasa saling memiliki antara komunitaskomunitas yang beraneka ragam (Parekh, 2008).

Pembangunan masyarakat multikultural menemukan makna sebenarnya ketika kohesi sosial berhasil dibangun di atas perbedaan-perbedaan Ritzen et, al. (2000). Dimensi kohesi sosial, akan menjadi modal sosial ketika sekelompok orang mampu menunjukkan kemampuannya untuk berkolaborasi dan menciptakan iklim perubahan. Kebhinekaan dalam kerangka kohesi sosial mensyaratkan terurainya hubungan sosial dikotomis pada lima aspek, sebagai berikut: (1) kebersamaan-isolasi (nilai-nilai bersama, identitas, perasaan, dan komitmen); (2) pengikutsertaan-pengesampingan (kesempatan yang adil setara untuk mendapatkan akses); (3) partisipasi-ketidakterlibatan (dalam politik, ekonomi, sosial, maupun budaya); (4) penerimaan-penolakan (menghargai dan mentoleransi perbedaan pada masyarakat majemuk); dan (5) legitimasi-ilegitimasi (adanya institusi-institusi yang berperan sebagai mediator konflik dalam masyarakat majemuk) (Berger-Schmitt, 2000). Dari kelima skema tersebut dapat dipahami bahwa kohesi sosial bertujuan memperkuat relasi, interaksi, dan ikatan sosial yang inheren dalam modal budaya (cultural capital), dengan meminimalisasi perbedaan, ketidakadilan, dan pengesampingan sosial. 


\section{Refleksi}

Disrupsi budaya merupakan kondisi ketidakpastian kultural karena nilai-nilai yang begitu beragam dan saling bertumpang tindih. Ini menjadi ancaman sekaligus peluang, tergantung pada kemampuan masyarakat dalam berinovasi di tengah perubahan. Bagi antropologi upaya kreatif imajinatif dan kritis dalam mengekplorasi potensi kemanusian atau studi etnografi (culture writting) menjadi keniscayaan agar studi-studi kebudayaan yang dihasilkan fakual, aktual, dan produktif bagi masyarakat dalam menyelami era disrupsi ini. Pergeseran ontologi kebudayaan, munculnya kritisme terhadap konsep dan makna etnosentrisme-relativisme kebudayaan, universalismepartikularisme, moderen-tradisional, outsider-insider, representasi, dan lainnya harus cepat disikapi dengan inovasi epsitemologis dengan menghindari pemikiran oposisi biner dan menghilangkan sekat-sekat disiplin yang kaku seiring mengaburnya batasbatas kebudayaan dalam masyarakat. Tugas antropologi tidak hanya berhenti pada upaya eksplorasi, memahami, dan menulis suatu kebudayaan atau studi etnografi untuk kita (antropologi), tetapi juga harus diorientasikan kearah praksis kebudayaan (acsiological dementions), yakni ikut berperan aktif dalam pembangunan, yakni penyadaran, pencerahan, dan pemberdayaan masyarakat. Keanekaragaman budaya bangsa harus ditransformasikan sebagai modal budaya untuk membangun masyarakat multikultural dengan memperkuat kohesi sosial. Kondisi ini akan terwujud jika studistudi kebudayaan mampu mengangkat kekayaan budaya bangsa sebagai kebanggaan spesifik. Lebih daripada itu, antropologi juga harus mampu mendekonstruksi berbagai praktik peminggiran, pendiskreditan, dan pendelegitimasian terhadap suatu komunitas budaya atas dasar ideologi meanstrem dominan karena sejatinya multikulturalisme menghendaki seluruh entitas budaya dapat hidup dan berkembang secara setara.

\section{Referensi}

Abdullah, Irwan. (1995). "Privatisasi Agama: Globalisasi atau Melemahnya Referensi Budaya Lokal?" Makalah Disampaikan dalam Seminar Sehari tentang Kharisma Warisan Budaya Islam di Indonesia "Islam dan Kebudayaan Jawa: Akulturasi, Perubahan dan Perkembangan". Balai Kajian Jarahnitra dan Depdikbud Daerah Istimewa Yogyakarta.

. (2006b). "Dari Bounded System ke Boundaries Society: Krisis Metode Antropologi dalam Memahami Masyarakat Masa Kini". Antropologi Indonesia, Vol. 30, No. 2, 2006.

(2006c). Konstruksi dan Reproduksi Kebudayaan. Yogyakarta: Pustaka Pelajar.

Anderson, B. (1999). Komunitas Imajiner: Renungan Tentang Asal-usul dan Penyebaran Nasionalisme. Terjemahan: Omi Intan Naomi. Yogyakarta: Pustaka Pelajar dan INSIST Press.

Appadurai, A. (1990). "Disjuncture and Difference in the Global Cultural Economy" in Mike Featherstone (Eds.). Global Cultural: Nationalism, Globalization, and Modernity. London: Sage Publications.

Ayatroehaedi. (1986). Kepribadian Budaya Bangsa (Local genius). Jakarta: Pustaka Jaya Barker, C. (2005). Culture Studies Teori dan Praktik. Yogyakarta: Bentang Pustaka.

Barnard, A, (2000). History and Theory in Anthropology. Cambridge University Press

Bellah, R.N. (1985). Tokugawa Religion: The Cultur Root of Modern Japan. New York: The Free Press. 
Depari, E., Mac'Andreus, C. (1998). Peranan Komunikasi Massa Dalam Pembangunan. Yogyakarta: Gadjah Mada University Press.

Eriksen, T.H.. (1993). Etnicity and Nationalisme: Antropological Perspectives. London and Boulder, Colorado: Pluto Press.

(2015). Small Places, Large Issues An Introduction to Social and Cultural Anthropology, Fourth Edition. London : Pluto Press.

Freidman, T.L. (2002). Lexus dan Pohon Zaitun. Bandung: Penerbit ITB.

Fukuyama, F. (1999). The Great Disruption: Human Nature and the Reconstruction of Social Order. London: Profiles Book.

Giddens, A. (2000). Runaway World: How Globalization Reshaping Our Lives. London: Profile Books Ltd.

Hannerz, U. (1990). "Cosmopolitans and Local in World Culture", in Mike Featherstone (Eds.). Global Cultural: Nationalism, Globalization, and Modernity. London: Sage Publications.

Hastrup, K, (1995). A Passage to Anthropology between experience and theory. London and New York: Routledge.

Huntington, S.P. (1996). The Clash of Civilization and The Remarking of World Other. New York: Simon \& Schuster.

Kellner, D. (2002). “Theorizing Globalization”, Sociologi Theory 20. pp. 285 - 305.

Kumbara, A.A. N. Anom, Suka, G. (Ed), (2017). Wacana Antropologi Membaca Ulang Teks Kebudayaan Menuju Transformasi Diri dalam Multikulturalisme. Prodi. Antropologi Fakultas Ilmu Budaya, Universitas Udayana.

Lewellen, C.T. (2002). The Anthropology of Globalization, Cultural Anthropology Enters the $21^{\text {st }}$ Century. USA: Bergin \& Garvey.

Lull, J. (1998). Media, Communication, Culture: A Global Approach. Cambridge: Polity Press.

McLuhan, M. (1994). Understanding Media: The Extension of Man. London: The MIT Press.

McPhail, T.L. (2014). Global Communication: Theories, Stakeholders and Trends. West Sussex: Wiley Blackwell Ltd.

Naisbitt, J. (1988). Megatrends: Global Paradox. New York: William Morrow and Company, Ltd.

Ochame, K. (1999). The Borderless World. Power and Strategy in the Interlinked Economy. Revision Edition. London: Profile Bussines.

Parekh, B. (2007). Rethinking Multikulturalism: Keberagaman Budaya dan Teori Politik. Yogyakarta: Kanisius.

Pilliang, Y.A. (1998). Dunia Yang Dilipat: Tamasya Melampaui Batas-batas Kebudayaan. Bandung: Pustaka Matahari.

Putnam, H. (1981). Reason, Truth and History. Cambridge: Cambridge University Press.

Robertson, R. (1992). Globalization: Social Theory and Global Culture. London, California, New Delhi: Sage Publications.

. (1995). "Glocalization: Time-Space and Homogeneity-Heterogeneity". In M. Featherstone, S. Lash, S. and Robertson, R., (Eds.). Global Modernities. London. Sage Publications.

Ritzen, J.W.E, Woolcock, M. (2000). "Good Politicians" and "Bad Policies": Social Cohesion, Institutions and Growth", in Policy Research Working Paper, Setember, 2448. Switzerland: World Bank.

Ritzer, G., Douglas J.G. (2005). Teori Sosiologi Modern. Jakarta: Prenada Media.

Sahlins, M. (1994). “Goodbye to Tristes Tropique: Ethnography in the Context of Modern World History', in R. Borofsky, (Eds.) Assessing Cultural Anthropology. New York: McGraw-Hill, Inc, Pp. 377-395.

Said, E. (2001). Orientalisme. Bandung: Penerbit Pustaka.

Storey, J. (2007). Culture Studies dan Kajian Budaya Pop. Yogyakarta: Jalasutra. 
Suaedy, A. (2007). Politisasi Agama dan Konflik Komunal Beberapa Isu Penting di Indonesia. Jakarta: The Wahid Institute.

Sutrisno, M. (2008). Refilosofi Kebudayaan. Yogyakarta: Kanisius.

Tilaar, H.A.R. (2004). Multikulturalisme Tantangan-tantangan Global Masa Depan dalam Transformasi Pendidikan Nasional. Jakarta: Grasindo.

Weber, Max. (1958). The Protestant Ethic and the Spirit of Capitalism. New York: Charles Scribner's Sons. 